\title{
Toward Hand Functions Rehabilitation Using the Virtual World for Pre-school Children with Cerebral Palsy
}

\author{
https://doi.org/10.3991/ijet.v15i09.13047 \\ Sana Sabah Sabry ( $\left.{ }^{\bowtie}\right)$, Mouayad A. Sahib, Thaker Nayl \\ University of Information Technology and Communications, Baghdad, Iraq \\ Sana.sabaheuoitc.edu.iq
}

\begin{abstract}
Cerebral Palsy (CP) is a collection of permanent, nonprogressive disorders that impact the individual's motor ability. The rehabilitation of patients with $\mathrm{CP}$ is very important to improve their motor abilities and to minimize the need for third parties. In this paper, a low-cost hand rehabilitation glove based on finger bend/pressure analysis is presented. The data glove is used to improve hand functioning for pre-school children with cerebral palsy through virtual reality games. The system consists of two parts: the data glove and several virtual games. The data glove consists of a microcontroller, flex sensors, force sensors and radiofrequency transmission units. The use of the newly-developed system will assist psychotherapists to follow the $\mathrm{CP}$ child daily, weekly or monthly. The rehabilitation model and the predicted physiotherapy results can be extracted from the patient's record after using the data. Experimental results have shown that the regular usage for the data glove improved $75 \%$ of the participants' fingers bending angle and the child's grip ability.
\end{abstract}

Keywords-Cerebral palsy, hand movement, flex sensor, force sensor, rehabilitation, virtual reality.

\section{$1 \quad$ Introduction}

Cerebral Palsy (CP) is a "collection of permanent, non-progressive disorders that impacts the individual's motor ability [1]. Other impairments can exist such as cognitive, language, and visual impairments" [2], which can affect the individual's daily activities. According to population-based studies [3, 4], the estimated prevalence of $\mathrm{CP}$ is estimated to be among 1.5 to almost 4 patients out of 1000 live births. $50 \%$ of them showed hand dysfunction [5].

Several problems can be seen with hand functioning in children with cerebral palsy, such as thumb abnormalities [6], wrist movement limitations, poor grasping abilities and low tweezers grip. These functions are necessary for the performance of the daily activity and for walking assistance tools utilization. The physiotherapy and rehabilitation process aim at improving hand function and to reduce the dependence in everyday life.

Different technologies may help the physiotherapists and can be used in order to offer new services that can optimize the quality of life and to help in the rehabilitation 
process, some of these technologies are: Internet of Things [7], Blockchain [8], Deep and Machine Learning [9] and Virtual Reality Game [10]. Virtual Reality Game (VRG) is the technology that allows its users to go through activities of experiments same as the events that happen in reality [11]. VRG is one of the most effective technologies and plays an extremely significant role in improving hand functions because it can motivate the $\mathrm{CP}$ child to repetitively open and close his fingers and move his wrist in different directions. Different VRG's elements can be utilized to recover many skills for the $\mathrm{CP}$ child such as repetition, feedback, motivation and training. [12].

During the past decade, many studies have been introduced in the literature about the application of VR in the medical field in general [13] and in the rehabilitation domain in particular [10, 14-17]. In [13], a review was presented about the current VR -based systems for medical application. In the rehabilitation sector, Ganesan et al. [18] presented a robotic glove upper limbs movement recovery. Rodriguez et al. [19] presented a 3-D rehabilitation system, with sensory feedback. Another study by Hatzigiannakoglou et al. [20] described a data acquisition wearable device for hand rehabilitation used for patients with hand movement impairment. The rotation of the hand is measured through tracks of gloves that are then translated using the MPU tool.

A more recent study employed an auricular-based training software to assist children having hearing aids such as cochlear implants whihc is likely to improve the auricular skills of audit and provide an opportunity to monitor their performance using Virtual Reality [21].

A few studies investigate the VR role in CP patients' treatment, for example in [22], the author used the leap motion and mind wave devices in the interaction of the user with the virtual environment, capturing the movements. With the aid of this system the specialists can direct the treatment in an individualized way to improve the treatment of motor rehabilitation. However, the proposed system is highly expensive.

As far as we know, no previous research has focused on the analysis of the preschool children with cerebral palsy hand functions improvement. Therefore, the need exists for a low-cost, in-house rehabilitation system for pre-school children with $\mathrm{CP}$ targeting the fingers bending and/or pressure. To address this need, we have developed a low-cost virtual-reality rehabilitation system consisting of two parts: a smart data glove and several virtual games. The data glove consists of microcontroller, flex and force sensors and radiofrequency transmission units. The system intends to motivate the child to grasp, and release virtual objects to win the game. Experimental results have shown that the regular usage for the data glove improves the child's ability to control/bend his fingers and boost his capability to grasp his hand.

The remaining part of the paper proceeds as follows: section 2 concerns with the system design details and the system implementation is presented in section 3. Analysis of the results is introduced in section 3. Finally, conclusions are given in section 4. 


\section{System Design}

To design the hand functioning rehabilitation system, several design specifications were set. Firstly, the data glove must be designed such that it will be lightweight, easy to wear and consumes low power. Secondly, the virtual game must be programmed in an attractive and easy way to be played by the child providing maximum hand rehabilitation benefits. Finally, the system must be informative for physicians to enable monitoring the child's hand movement parameters such as bend and/or presser ability.

The hand-rehabilitation system consists of a data glove and computer-based VRG. The overall system architecture is shown in figure 1 .

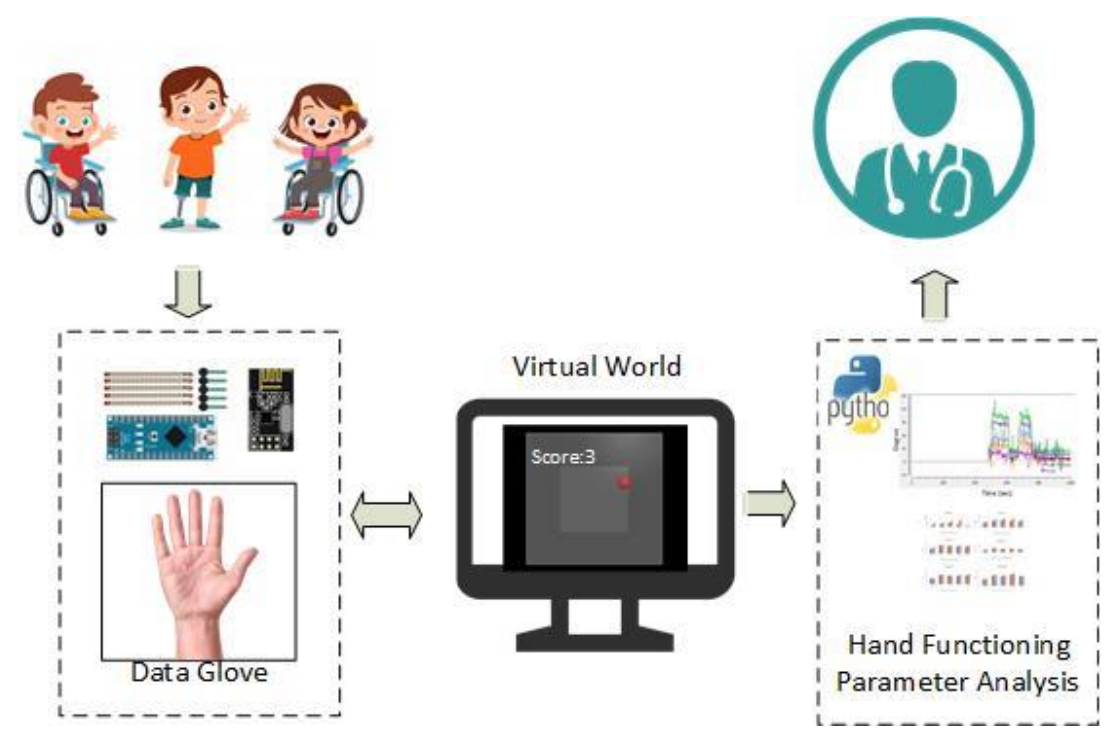

Fig. 1. System implementation

The basic idea of the rehabilitation system is to allow the child to interact with an attractive virtual game using various activities of his hand and fingers. The interaction is performed through a smart data glove provided with flex and force sensors. The smart data glove is connected to a PC through a wireless radiofrequency transmission unit. The PC represents the virtual world in which the child can interact with. The PC can record all the bending and presser data to monitor treatment progress.

\subsection{Mathematical model of the human hand}

To understand how the flex sensor is used to measure the finger bending and the sensor position on the data glove, the hand model is presented in this section. As shown in figure 2, there is an important structural part of the finger's movement measurement. It has been separated into one Interphalangeal Joint with four Proximal Interphalangeal Joints (PIP). It is the capability of the sensor located on the finger's 
surface to notice the Metacarpophalangeal movement with the ability to measure 10 DOF or more of the hand.

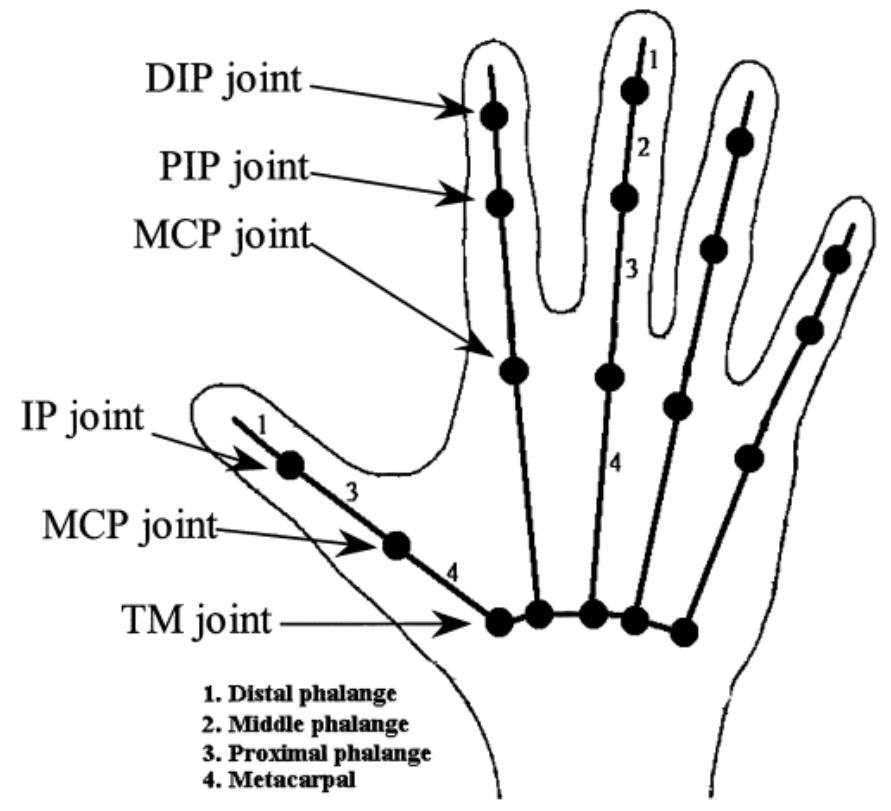

Fig. 2. Hand's kinematic [23]

In particular, the hand fingers can use equation (1)

$$
\theta_{D I P}=0.67 \theta_{P I P}
$$

Where, $\theta_{D I P}$ is the bending angle related to DIP joints of fingers and $\theta_{P I P}$ is PIP joint's bending angle. The movement of the finger usually ranges between these limits:

$$
\begin{gathered}
0^{\circ} \leq \theta_{\text {PIP-Flexion }} \leq 90^{\circ} \sim 100^{\circ} \\
0^{\circ} \leq \theta_{\text {thumb-IP-flexion }} \leq 90^{\circ} \\
0^{\circ} \leq \theta_{M C P-\text { Flexion }} \leq 90^{\circ}
\end{gathered}
$$

\subsection{Smart data glove}

The data glove is designed and tested for hand function rehabilitation assistance. It is intended to be easy to wear and lightweight. The proposed glove system consists of 5 flex sensors, 5 force sensors, microcontroller and radio frequency (RF) transmitter. The glove can measure parameters such as finger's bending, hand grasp ability and the child's ability to control his fingers. The movement of the finger is precisely represented by these parameters at the time of the patients' rehabilitation performance of 
their exercise while virtual games are played. It is important to locate the sensors carefully to exactly measure the movement of the finger. The sensors are preferred to be placed on the position of the finger's joints. The force sensors, on the other hand, are installed on the hand's palmer surface. The flex sensors can measure the bend angle for each finger, and the force sensors can measure the child's ability to grasp his hand. The controller circuit is located on the wrist, which consists of a microcontroller, (nRF24l) RF transmitter and a 1000-mA Li-polymer battery, which collect the readings and sends them to a computer-based virtual game. The system's sampling rate is $50 \mathrm{sample/sec.} \mathrm{The} \mathrm{smart} \mathrm{data} \mathrm{glove} \mathrm{system} \mathrm{is} \mathrm{shown} \mathrm{in} \mathrm{figure} 3$.

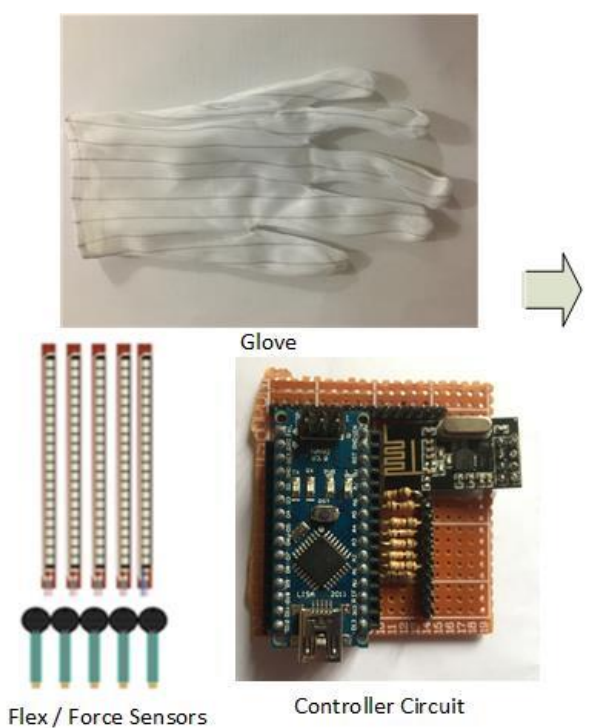

Fig. 3. Smart data glove

\subsection{Virtual world games environment}

The virtual game environment was developed in python 3.7. Two scenarios were designed during the study as shown in figure 4. The first scenario was "Grasp the ball" in which the child must press his fingers to score extra points, this helps the child to control and improve his grasp ability.

In the second scenario, the $\mathrm{CP}$ child must bend each finger individually to score extra points. This can improve the child's ability to control his fingers.

The game's feedback is very valuable to encourage the child to continue playing the game. For the proposed system, whenever the child correctly performs a goal, feedback must be given. 

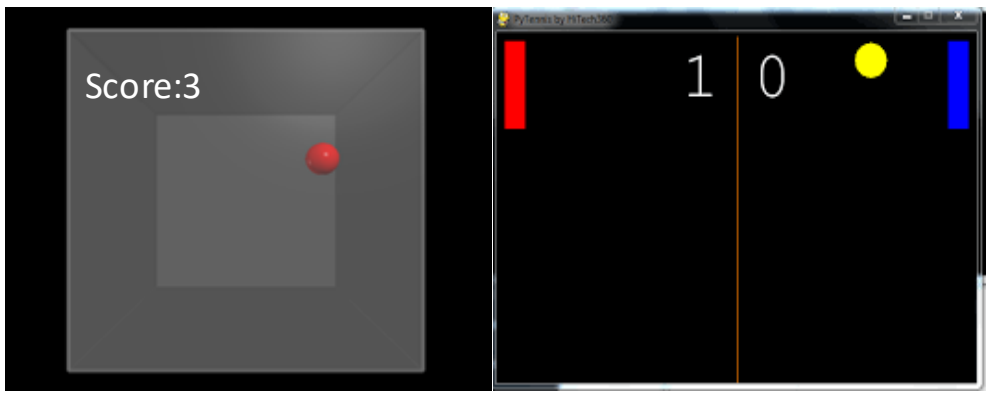

Fig. 4. The proposed games scenarios

An experiment was conducted in the Rehabilitation Medical Centre and Joint Diseases, Iraq. All children of age 5-12 years, received two game sessions of $30 \mathrm{~min}$ every day as illustrated in figure 5 .
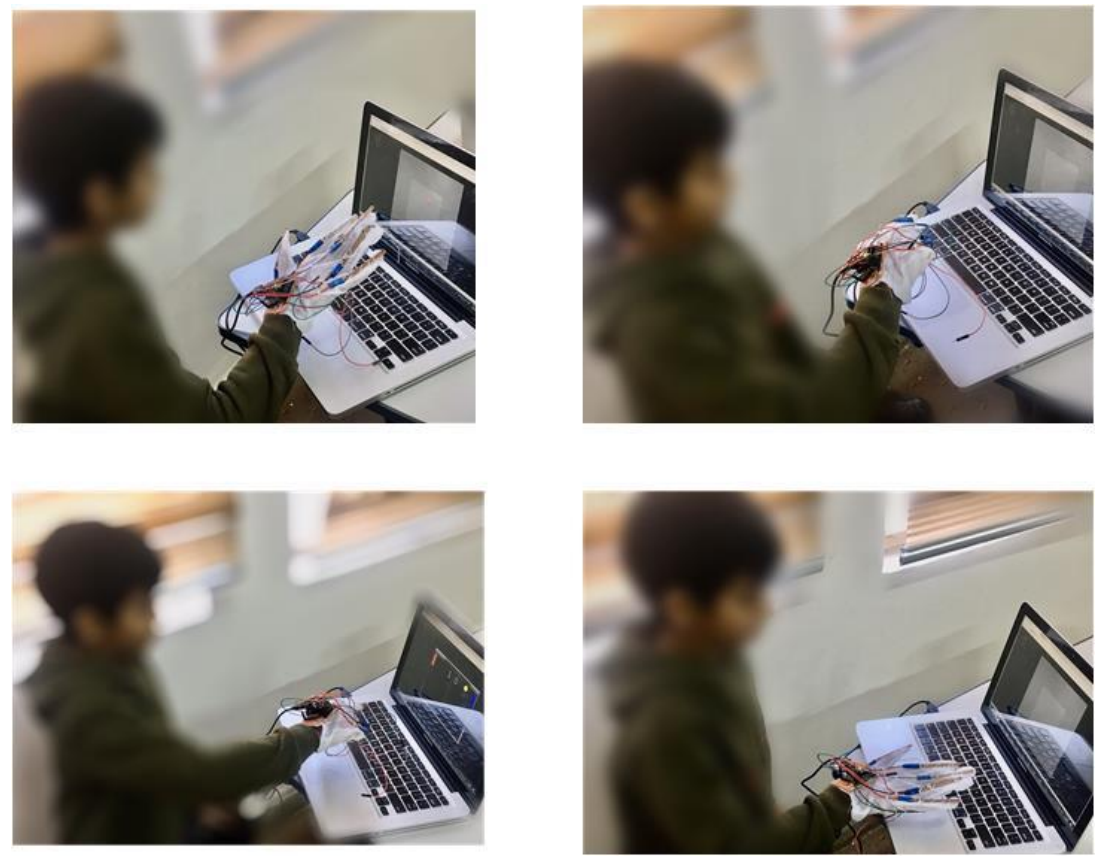

Fig. 5. System implementation

\section{$3 \quad$ Results}

Patients were evaluated individually considering the evolution during the usage of the proposed system. During rehabilitation sessions, data are collected and stored in the patient's health record, so they can be reachable for physiotherapists. For each hand, the collected data are: 
- The Flex Sensors sense the angular flexion and compression for each finger. The values are stored in degrees $\left(0\right.$ to $\left.90^{\circ}\right)$.

- The FlexiForce Sensors sense the pressure force values exerted by each fingertip on each hand.

The data is stored in a CSV format to facilitate future analysis. An image for the .csv file data organization is presented in figure 6 .

\begin{tabular}{|c|c|c|c|c|c|c|c|c|c|c|}
\hline 1 & Pat-ID & Iter & & Date & Time & F1_ang & F2_ang & F3_ang & F4_ang & F5_ang \\
\hline 2 & & 1 & 1 & $1 / 5 / 2020$ & 21:56.4 & 4 & 11 & 31 & 41 & 32 \\
\hline 3 & & 1 & 2 & $1 / 5 / 2020$ & 21:56.5 & 4 & 11 & 31 & 41 & 32 \\
\hline 4 & & 1 & 3 & $1 / 5 / 2020$ & 21:56.6 & 4 & 11 & 31 & 41 & 32 \\
\hline 1 & Pat-ID & Iter & & Date & Time & F1_force & F2_force & F3_force & F4_force & F5_force \\
\hline 2 & & 1 & 1 & $1 / 2 / 2020$ & $03: 56.0$ & 200 & 187 & 200 & 150 & 70 \\
\hline 3 & & 1 & 2 & $1 / 2 / 2020$ & 03:57.0 & 205 & 177 & 200 & 150 & 70 \\
\hline
\end{tabular}

Fig. 6. CSV file data organization

The bending information was used to analyze the CP child's ability to bend his fingers, while the pressure reading was used to analyze the child's ability to grasp his hand. To simplify the analysis of the readings, the F1 readings correspond to Pinky Finger, The F2 readings correspond to Ring Finger, The F3 readings correspond to Middle Finger, the F4 readings correspond to Index Finger and the F5 readings correspond to Thumb Finger.

Two types of activities were measured, the fingers' ability to bend (fingers control) and the fingers' ability to press (hand grip).

\subsection{Bend measurements}

The fingers ability to bend is tested through measurements of a CP child and compared with a normal one. figure 7 shows the angular flexion of each right-hand finger for both $\mathrm{CP}$ and normal child. It can be observed from figure 7 that the fingers bending angle value ranges from 0 to 90 degrees. While for a CP child, the fingers bend angle values range from 0 to 40 degrees, except the thumb finger, with a bend angle from 0 to 20 degrees. $80 \%$ of the participants suffer from the same problem. Moreover, it can be noticed that the $\mathrm{CP}$ child has poor finger control in general and poor thumb control in particular. Repeating the measurements regularly for six weeks by implementing the proposed system, we found that $75 \%$ of the participant experience in fingers control was improved, except for the thumb finger (F5), which experienced less improvement. Table 1, lists the numerical results of the measurements. The results are recorded after taking the readings averages of the fingers' bending angles. Also, the results were plotted in figure. 8 . 


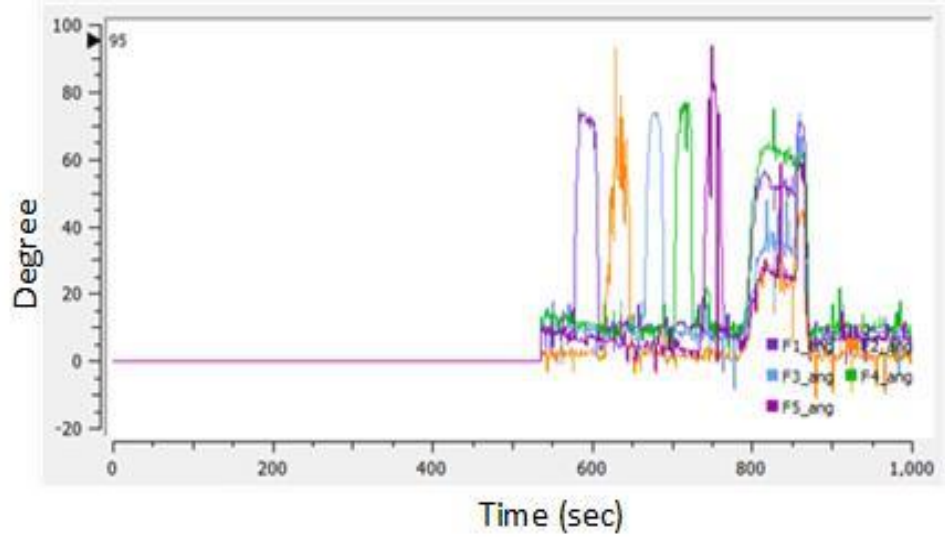

(a) Normal child

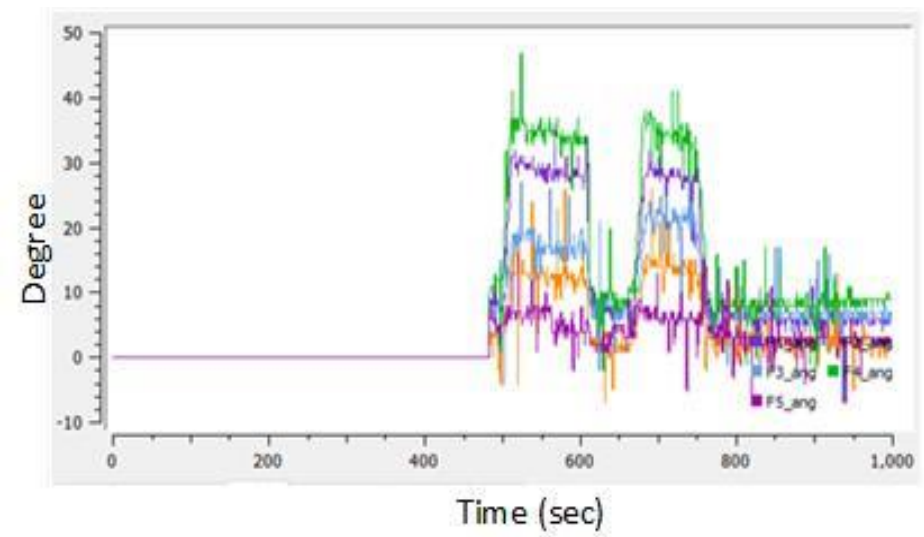

(b) CP child

Fig. 7. Angular flexion/compression for each finger (right hand)

Table 1. Fingers' bending angles before and after system implementation

\begin{tabular}{|c|c|c|c|c|c|c|c|c|c|c|}
\hline \multirow{2}{*}{ Patient ID } & \multicolumn{5}{|c|}{$\begin{array}{c}\text { Bending angles (degrees) } \\
\text { Before System Implementation }\end{array}$} & \multicolumn{5}{|c|}{$\begin{array}{l}\text { Bending angles (degrees) } \\
\text { After } 6 \text { weeks of system implementation }\end{array}$} \\
\hline & $\begin{array}{c}F 1 \_a n \\
g\end{array}$ & F2_ang & F3_ang & F4_ang & F5_ang & $F 1$ ang & F2_ang & F3_ang & F4_ang & F5_ang \\
\hline 1(mild) & 30 & 32 & 33 & 40 & 11 & 42 & 44 & 44 & 50 & 25 \\
\hline 2(mild) & 35 & 33 & 39 & 44 & 9 & 46 & 47 & 46 & 52 & 15 \\
\hline 3 (moderate) & 36 & 32 & 30 & 39 & 9 & 42 & 38 & 37 & 44 & 15 \\
\hline 4 (moderate) & 25 & 26 & 23 & 29 & 7 & 33 & 33 & 29 & 38 & 13 \\
\hline \begin{tabular}{|l|} 
5(moderate) \\
\end{tabular} & 35 & 30 & 31 & 35 & 7 & 41 & 38 & 40 & 39 & 10 \\
\hline 6(severe CP) & 19 & 17 & 17 & 20 & 5 & 19 & 16 & 19 & 21 & 5 \\
\hline 7(severe $\mathrm{CP})$ & 20 & 21 & 20 & 25 & 4 & 22 & 20 & 20 & 25 & 6 \\
\hline
\end{tabular}




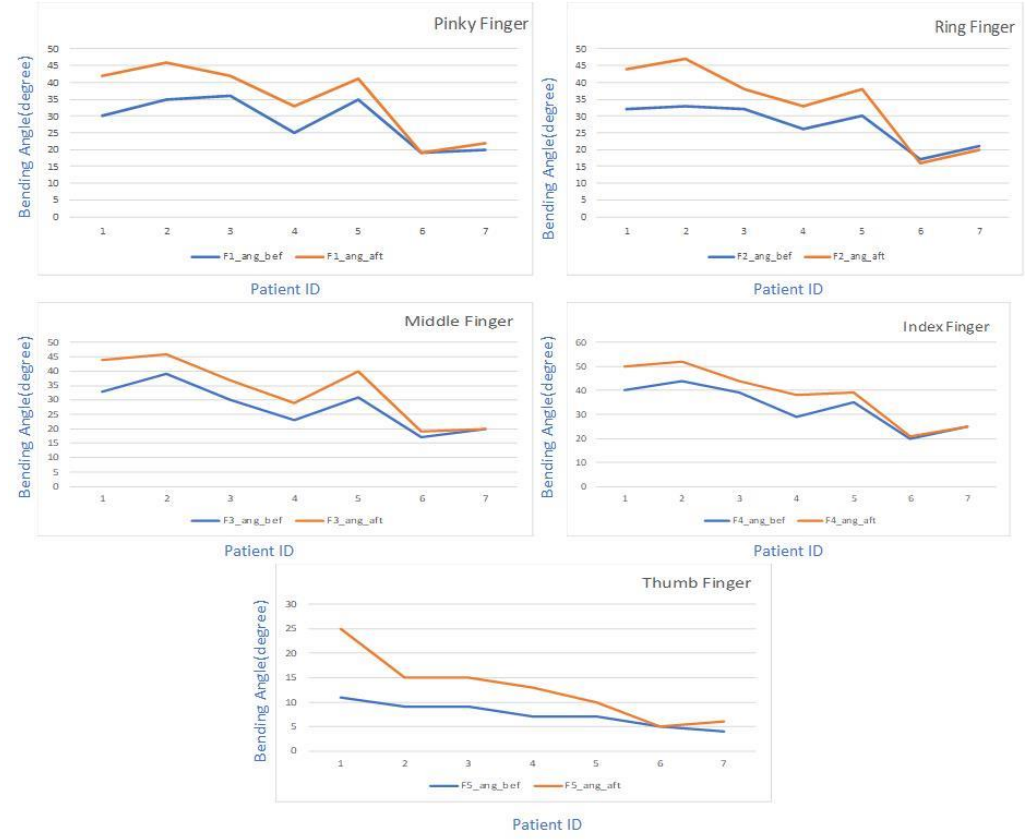

Fig. 8. Fingers' bending before and after system implementation

\subsection{Grip measurement}

All types of forces that are applied on each finger's tip can be observed through the reading of the Flexi force during the open and closed hand's movement. The values recorded in figure 9, show the normal child in comparison with a $\mathrm{CP}$ child. The normal child scores an average of 500 force value. However, a CP child, on the other hand, scores an average of 50 force value. This indicates a palsy of $90 \%$ in gripping ability compared to a normal child. From the same figure, the poor pressure ability for the CP child's thumb can be also noticed.

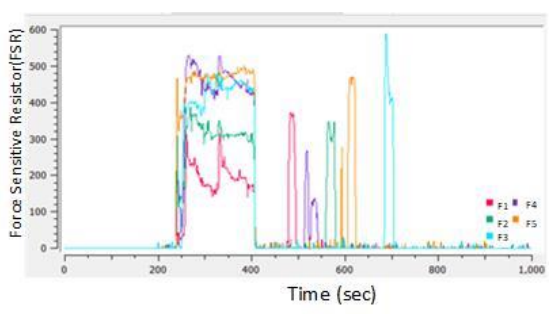

(a) Normal child

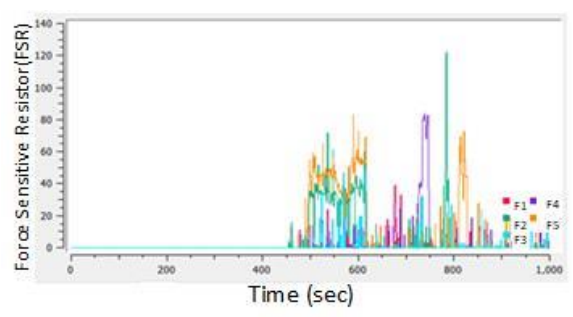

(b) CP child

Fig. 9. The pressure force values exerted by each fingertip (right hand) 
Patients experienced less improvement in the hand grip ability, because such function need more than 6 weeks of exercises according to the doctors and physiotherapists' recommendations. Table 2 and figure 10 show the pressure force values exerted by each fingertip.

Table 2. The pressure force values exerted by each fingertip

\begin{tabular}{|l|c|c|c|c|c|c|c|c|c|c|}
\hline \multirow{2}{*}{ Patient ID } & \multicolumn{4}{|c|}{ Before System Implementation } & \multicolumn{4}{c|}{ After 6 weeks of system implementation } \\
\cline { 2 - 12 } & $\boldsymbol{F 1}$ & $\boldsymbol{F 2}$ & $\boldsymbol{F 3}$ & $\boldsymbol{F 4}$ & $\boldsymbol{F 5}$ & $\boldsymbol{F 1}$ & $\boldsymbol{F 2}$ & $\boldsymbol{F 3}$ & $\boldsymbol{F 4}$ & $\boldsymbol{F 5}$ \\
\hline 1(mild) & 40 & 80 & 120 & 80 & 30 & 113 & 111 & 166 & 200 & 30 \\
\hline 2(mild) & 43 & 60 & 65 & 55 & 53 & 49 & 69 & 77 & 76 & 69 \\
\hline 3(moderate) & 30 & 55 & 49 & 44 & 45 & 40 & 50 & 48 & 51 & 45 \\
\hline 4(moderate) & 33 & 57 & 48 & 48 & 45 & 35 & 59 & 49 & 50 & 44 \\
\hline 5(moderate) & 35 & 55 & 50 & 49 & 51 & 35 & 56 & 51 & 55 & 59 \\
\hline 6(moderate) & 33 & 53 & 50 & 60 & 51 & 35 & 59 & 54 & 65 & 50 \\
\hline 7(severe CP) & 0 & 0 & 0 & 0 & 0 & 0 & 0 & 0 & 0 & 0 \\
\hline 8(severe CP) & 2 & 5 & 10 & 10 & 0 & 2 & 5 & 10 & 10 & 0 \\
\hline
\end{tabular}

Patients with severe cerebral palsy (Pat.7, Pat.8) show no improvent in the hand's grip ability. From the table above, $75 \%$ of the participants show improvement of hand grip ability, and only two of them show significant improvement.

\section{Conclusion}

Cerebral Palsy is a collection of permanent, non-progressive disorders that impact the individual's motor ability. Other impairments can exist such as cognitive, language, and visual impairment, which can affect the individual's daily activities. 50\% of CP children show a hand dysfunction. Virtual Reality Game (VRG) can play an important role to achieve this goal because the VRGs can motivate the CP child to repetitively open and close his fingers and move his wrist in different directions. Different VRG's elements such as repetition, feedback, motivation and training can be utilized to recover many skills for the $\mathrm{CP}$ child. Therefore, the need exists for a lowcost, in-house rehabilitation system for pre-school children with $\mathrm{CP}$ targeting the fingers bending /pressure. To address this need, we have developed a low-cost virtual -reality rehabilitation system which consists of two parts: a smart data glove and several virtual games. The data glove consists of a microcontroller, flex sensors and force sensors and radiofrequency transmission unit.

The system motivated the child to grasp, and release virtual objects to win the game. The strength of grip can be improved through this rehabilitation type that is considered to be rehabilitation's last stage. Additionally, information related to the pressure helps the physiotherapists in restraining the force of patients if their pain occurs due to the finger's motion.

The Experimental results have shown that the regular usage for the data glove improved the child's ability to control/bend his fingers and boost his capability to grasp his hand. 

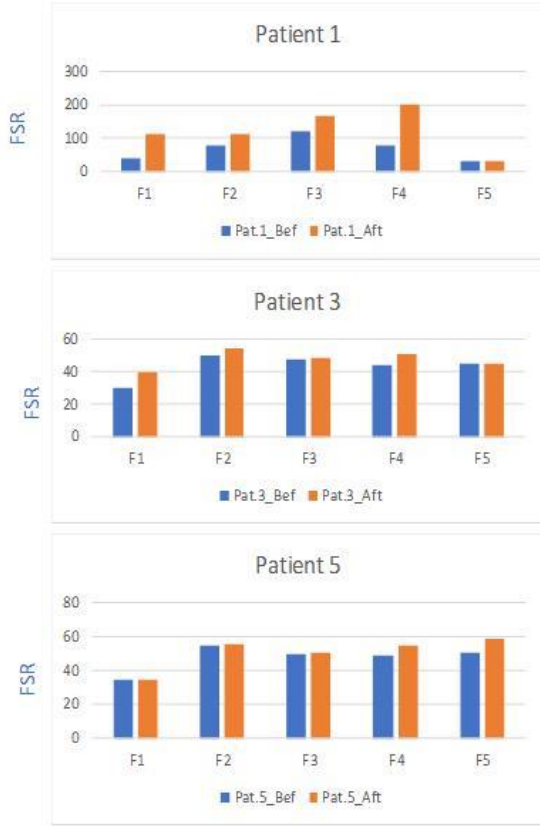

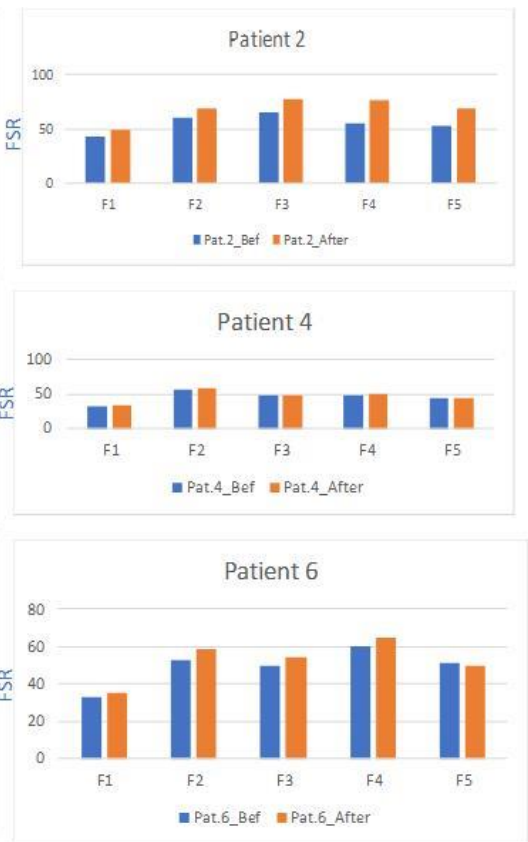

- Pat.6_Bef $=$ Pat.6_After

Fig. 10.The pressure force values exerted by each fingertip

\section{Acknowledgements}

We would like to thank the Rehabilitation Medical Centre and Joint Diseases, Iraq for providing us with all the support towards the successful implementation of the study

\section{References}

[1] M. Bax, M. Goldstein, P. Rosenbaum, A. Leviton, N. Paneth, B. Dan, et al., "Proposed definition and classification of cerebral palsy, April 2005," Developmental medicine and child neurology, vol. 47, pp. 571-576, 2005. https://doi.org/10.1017/s001216220500112x

[2] E. Odding, M. E. Roebroeck, and H. J. Stam, "The epidemiology of cerebral palsy: incidence, impairments and risk factors," Disability and rehabilitation, vol. 28, pp. 183-191, 2006. https://doi.org/10.1080/09638280500158422

[3] A. Johnson, "Prevalence and characteristics of children with cerebral palsy in Europe," Developmental medicine and child neurology, vol. 44, pp. 633-640, 2002. https://doi.org/ 10.1111/j.1469-8749.2002.tb00848.x

[4] C. L. Arneson, M. S. Durkin, R. E. Benedict, R. S. Kirby, M. Yeargin-Allsopp, K. V. N. Braun, et al., "Prevalence of cerebral palsy: autism and developmental disabilities monitoring network, three sites, United States, 2004," Disability and health journal, vol. 2, pp. 4548, 2009. https://doi.org/10.1016/j.dhjo.2008.08.001 
[5] C. Arnould, Y. Bleyenheuft, and J.-L. Thonnard, "Hand functioning in children with cerebral palsy," Frontiers in neurology, vol. 5, p. 48, 2014. https://doi.org/10.3389/fneur.2014. $\underline{00048}$

[6] E. S. Park, E. G. Sim, and D.-w. Rha, "Effect of upper limb deformities on gross motor and upper limb functions in children with spastic cerebral palsy, "Research in developmental disabilities", vol. 32, pp. 2389-2397, 2011. https://doi.org/10.1016/j.ridd.2011.07.021

[7] S. S. Sabry, N. A. Qarabash, and H. S. Obaid, "The Road to the Internet of Things: a Survey," in 2019 9th Annual Information Technology, Electromechanical Engineering and Microelectronics Conference (IEMECON), 2019, pp. 290-296. https://doi.org/10.1109/ie meconx.2019.8876989

[8] S. S. Sabry, N. M. Kaittan, and I. M. Ali, "The road to the blockchain technology: Concept and types."

[9] S.-C. Yeh, M.-C. Huang, P.-C. Wang, T.-Y. Fang, M.-C. Su, P.-Y. Tsai, et al., "Machine learning-based assessment tool for imbalance and vestibular dysfunction with virtual reality rehabilitation system," Computer methods and programs in biomedicine, vol. 116, pp. 311-318, 2014. https://doi.org/10.1016/j.cmpb.2014.04.014

[10] O. Halabi, S. A. El-Seoud, J. M. Alja'am, H. Alpona, M. Al-Hemadi, and D. Al-Hassan, "Design of Immersive Virtual Reality System to Improve Communication Skills in Individuals with Autism," International Journal of Emerging Technologies in Learning, vol. 12, 2017. https://doi.org/10.3991/ijet.v12i05.6766

[11] V. Lamb, "Teaching motor skills to children with cerebral palsy and similar movement disorders: a guide for parents and professionals," Pediatric Physical Therapy, vol. 19, pp. 340-341, 2007. https://doi.org/10.1097/pep.0b013e31815b5d57

[12] P. L. Weiss, E. Tirosh, and D. Fehlings, "Role of virtual reality for cerebral palsy management," Journal of child neurology, vol. 29, pp. 1119-1124, 2014. https://doi.org/10.117 $\underline{\text { 7/0883073814533007 }}$

[13] L. Li, F. Yu, D. Shi, J. Shi, Z. Tian, J. Yang, et al., "Application of virtual reality technology in clinical medicine," American journal of translational research, vol. 9, p. 3867, 2017.

[14] M. Iosa, G. Morone, A. Fusco, M. Castagnoli, F. R. Fusco, L. Pratesi, et al., "Leap motion controlled videogame-based therapy for rehabilitation of elderly patients with subacute stroke: a feasibility pilot study," Topics in stroke rehabilitation, vol. 22, pp. 306-316, 2015. https://doi.org/10.1179/1074935714z.0000000036

[15] N. J. Seo, J. A. Kumar, P. Hur, V. Crocher, B. Motawar, and K. Lakshminarayanan, "Usability evaluation of low-cost virtual reality hand and arm rehabilitation games," Journal of Rehabilitation Research \& Development, vol. 53, 2016. https://doi.org/10.1682/jrrd.2015. $\underline{03.0045}$

[16] A. Henderson, N. Korner-Bitensky, and M. Levin, "Virtual reality in stroke rehabilitation: a systematic review of its effectiveness for upper limb motor recovery," Topics in stroke rehabilitation, vol. 14, pp. 52-61, 2007. https://doi.org/10.1310/tsr1402-52

[17] A. Setiawan, F. Agiwahyuanto, and P. Arsiwi, "A Virtual Reality Teaching Simulation for Exercise During Pregnancy," International Journal of Emerging Technologies in Learning, vol. 14, 2019. https://doi.org/10.3991/ijet.v14i01.8944

[18] S. Ganeson, R. Ambar, and M. M. A. Jamil, "Design of a low-cost instrumented glove for hand rehabilitation monitoring system," in 2016 6th IEEE International Conference on Control System, Computing and Engineering (ICCSCE), 2016, pp. 189-192. https://doi. org/10.1109/iccsce.2016.7893569

[19] A. Rodriguez, X. Li, and W. Yu, "A 3-D hand rehabilitation system using haptic device," in 2015 12th International Conference on Electrical Engineering, Computing Science and Automatic Control (CCE), 2015, pp. 1-6. https://doi.org/10.1109/iceee.2015.7357909 
[20] R. Tavares, P. Abreu, and M. R. Quintas, "Data Acquisition Glove for Hand Movement Impairment Rehabilitation," International Journal of Online Engineering (iJOE), vol. 12, pp. 52-54, 2016. https://doi.org/10.3991/ijoe.v12i04.5141

[21] P. D. Hatzigiannakoglou and A. Okalidou, "Development of an Auditory Rehabilitation Tool for children with Cochlear Implants through a Mobile-Based VR and AR serious game," International Journal of Online Engineering, vol. 15, 2019. https://doi.org/10.3991/ ijoe.v15i02.9709

[22] J. M. de Oliveira, R. Munoz, S. Ribeiro, W. Wu, and V. H. C. de Albuquerque, "REHAB FUN: an assistive technology in neurological motor disorders rehabilitation of children with cerebral palsy," Neural Computing and Applications, pp. 1-14, 2019. https://doi.org/ $10.1007 / \mathrm{s} 00521-019-04059-2$

[23] C.-S. Fahn and H. Sun, "Development of a data glove with reducing sensors based on magnetic induction," IEEE Transactions on Industrial Electronics, vol. 52, pp. 585-594, 2005. https://doi.org/10.1109/tie.2005.844259

\section{Authors}

Sana Sabah Sabry was born in Basrah, Iraq in 1986. She received her B.S. degree in computer Engineering from Al-Nahrain University, Iraq, in 2008 and her M.S. in Control Engineering from Al-Nahrain University, Iraq, in 2011. She has 10 years' work experience at different educational organizations. She is currently a lecturer in the college of engineering at the university of information technology and communications (UOITC), Baghdad, Iraq. Her research topics include control theory, optimization algorithms, Internet of Things, robotics, motion tracking. She can be contacted via email: sana.sabah@uoitc.edu.iq.

Mouayad A. Sahib received the B.Sc. degree in Electrical Engineering and the M.Sc. degree in Computer and Control Engineering from the University of Baghdad, Iraq, in 1998 and 2003, respectively, and the Ph.D. degree in control and automation from University Putra Malaysia, in 2012. In 2003, he joined the Department of Computer Engineering, University of Baghdad as a lecturer. He is now a full-time professor at the College of Engineering, University of Information Technology and Communications, Baghdad, Iraq. His research interests include intelligent control systems, adaptive control and signal processing, and non-linear adaptive algorithms.

Thaker Nayl is a senior lecturer at the College of Engineering, University of Information Technology and Communications. He has received his Ph.D. degree in Automatic Control Engineering from Luleå University of Technology, Sweden. His research activities are focusing in the areas of classical and advanced controllers, modelling kinematic systems, design sliding mode controllers, and model predictive controllers.

Article submitted 2020-01-16. Resubmitted 2020-02-01. Final acceptance 2020-02-02. Final version published as submitted by the authors. 